Brit. F. vener. Dis. (1970) 46, 243

\title{
Promiscuity and contraception in a sample of patients attending a clinic for venereal diseases
}

\author{
A. LINKEN \\ Student Health Association, University College, London, and Fames Pringle House, Middlesex Hospital, London
}

R. S. P. WIENER

Conflict Research Unit, London School of Economics

THE alarming increase in the incidence of venereal disease in the world, particularly among young people, presents a problem that must be tackled on several fronts. These include medical treatment, dealing with defaulters from clinics, contact tracing, and health education. There is also a need to discover more about those who attend clinics, partly to aid treatment programmes and partly to introduce effective preventive measures.

We are especially concerned about the reported increase in promiscuity which, coupled with inadequate or insufficiently used facilities for advice on contraception, is causing an apparent increase in the number of abortions among young people. There is a need for some factual data on the number of abortions and the public's awareness and use of different methods of contraception.

The aim of this small pilot study was to examine the characteristics of patients attending a clinic for venereal diseases and the use and consequences of failure to use contraceptive techniques amongst this sexually active population. It was hoped to obtain data on the relationship between the use of the pill and sexually promiscuous behaviour, and to assist the design of educational material in the fields of venereal disease and contraception and the development of advisory and contraceptive clinics for young people at special risk.

\section{Method}

Separate questionnaires were designed (by R.S.P.W.) for male and female patients, that for the latter being more comprehensive. These were distributed to patients attending a clinic attached to a hospital in London during one week of January, 1969. The patients were unselected and the questionnaires were handed to them as they awaited the results of their tests, after having seen the doctor. They were told that the questionnaires were designed to assist in long-term treatment and that their

Received for publication August 1, 1969. answers would be treated in the strictest confidence. The questionaires were not designed for homosexual or illiterate patients and these were excluded from the sample although bisexual patients were included.

It was originally intended to have 100 male and 100 female patients in the sample, but in the event questionnaires were given to 61 men and 92 women. Seventeen men and two women failed to answer and one woman's answer was disqualified because of inconsistencies; this left a sample of 44 men and 89 women.

\section{Results}

(1) THE SAMPLE

All the 44 male patients were aged 20 years or over, 70 per cent. being in the 20 to 30 -year age group. Of the 89 females, 10 per cent. were aged 16 to 19 years and 84 per cent. 20 to 30 years. 82 per cent. of the men and 71 per cent. of the women were single. The married men and women tended to be older than the single patients.

(2) PREGNANCY, ABORTION, MISCARRIAGE, AND OFFSPRING

Of the 63 women who were single or engaged, fifteen had been pregnant at least once and four more than once.

Fifteen patients reported at least one abortion; two had had two abortions and one had had four. Of these fifteen women, nine were single, one was engaged, one was married and living with her husband, two were married and separated, one was divorced, and one was widowed.

Ten women reported having had one miscarriage and three had had two; of these thirteen patients one was single and two were engaged.

Four of the unmarried female patients had had one child each; three of these children had been adopted and one was in a foster home.

\section{(3) NUMBER OF SEXUAL PARTNERS}

The males were more promiscuous than the females, 84 per cent. having had intercourse with more than 
one partner in the previous 6 months compared to only 41 per cent. of the females; 45 per cent. of the males had had four or more partners compared to 17 per cent. of the females.

The single subjects were more promiscuous than the married ones. Only one of the seven married men had had more than two partners compared to 25 of the 37 single men. Similarly only two of the fourteen married women who lived with their husbands had had more than one partner, although one of the two had had four partners and the other seven. Of the single and engaged girls 47 per cent. had had only one partner in the previous 6 months, compared to 11 per cent. of the unmarried men.

\section{(4) FREQUENCY OF INTERCOURSE}

The average figures for males and females are similar; 43 per cent. of the males and 51 per cent. of the females had had sexual intercourse two to four times a week or more during the previous 6 months, 20 per cent. of the males and 18 per cent. of the females once a week, and 16 per cent. of the males and 9 per cent. of the females fortnightly.

The married subjects, as might be expected, had sexual intercourse more frequently than the single subjects; six of the seven married men had intercourse as frequently as two to four times a week, whereas only thirteen of the 36 single men had intercourse this frequently. Similarly, twelve out of the fourteen married women had intercourse two to four times a week compared to only 26 of the 63 single women.

\section{(5) CONTRACEPTION}

25 per cent. of the males and 18 per cent. of the females said that they never used any form of contraceptive. The majority of the male patients said that they 'left it all to the woman'. The figures suggest that 45 per cent. of the men use contraceptives only occasionally and that 28 per cent. of the females use contraceptives occasionally or not at all.

Whereas three of the seven married men always used contraceptives, nineteen of the 37 single men used contraceptives only part of the time. Among the female subjects, sixteen of the 25 women who were or had been married always used contraceptives compared to 42 of the 63 who had never been married. The difference between these two groups appears in the numbers who never used any form of contraceptive. Fourteen of the women who had never been married never used any form of contraceptive compared to only two of those who had been married.

Approximately 45 per cent. of the men, both promiscuous and non-promiscuous, ${ }^{\star}$ used contraceptives

* Subjects who had had intercourse with more than one partner over the past 6 months were defined as being promiscuous. only occasionally. Only five of the 53 non-promiscuous females compared to eleven of the 36 promiscuous females said they never used contraceptives.

Only five of the nineteen sexually active $\dagger$ men said they used contraceptives only part of the time compared to fifteen of the remaining 25 men. Only three of the 46 sexually active women said they never used contraceptives compared to thirteen of the 43 remaining women.

\section{(6) TYPE OF CONTRACEPTIVE USED}

Men The sheath was by far the most frequently used contraceptive, though the majority of men who were sexually most active, left contraception to the woman. Among the small sample of non-promiscuous males withdrawal was mentioned as frequently as the sheath as a method of contraception.

Women The pill was used 'always' by 49 of the 89 women and had been used 'sometimes' by five others. It was, therefore, by far the most popular form of contraceptive. The second most frequently mentioned method was withdrawal. The predominance of the pill was greatest among the patients who were sexually active, promiscuous, and married. Withdrawal was used comparatively more often by those who were single, and both the sheath and withdrawal were used comparatively frequently by partners of the less sexually active and non-promiscuous female patients.

\section{Discussion}

This enquiry was undertaken among a group of patients attending a clinic for venereal disease in the centre of London, catering for a wide selection of the population, including students and business men as well as 'fringe' individuals, 'hippies', and 'drop-outs'. The sample was not specifically taken from patients suffering from venereal disease since it included subjects who had other sexually transmitted diseases and some who attended for routine check-ups.

The males in the series were all 20 years old or over, but 61 per cent. were aged from 20 to 27 years. The male sample was comparatively small, and as such might be considered atypical of the male population attending this particular centre. A previous enquiry into drug taking among patients attending a centre for venereal diseases showed that 14 per cent. were under the age of 20 years (Linken, 1968).

The female sample, which was much larger and more consistent with the women included in the drugtaking sample, showed 10 per cent. in the 16 to 19 year age range and 78 per cent. in the 20 to 27 year age range. These findings correspond to the known facts about sexually transmitted disease, the foremost

tThose who had had sexual intercourse two to four times a week or more during the last 6 months were defined as sexually active. 
being the increased risk of disease in the younger age groups. Of no less importance is the fact that the majority of women at risk were unmarried or engaged. In our sample 82 per cent. of the men and 71 per cent. of the women were unmarried. Schofield (1968) found that, by the age of 16 years, 14 per cent. of the boys and 5 per cent. of the girls in his sample had had experience of sexual intercourse. By the time they were 18 years old, the proportion of girls with experience had risen to 17 per cent. We have the figures for the female sample only, but 20 per cent. of them had had sexual experience before their 16th birthday, 38 per cent. at 17 or 18 years, and 26 per cent. at 19 or 20 years. We could argue that our results are an expression of the effects of our permissive society on sexual behaviour, but it is more likely that this sample represents a highly selected group of young sexually active people specifically at risk of contracting venereal diseases. Obviously, as the sample is confined to only one week in one year at one clinic, not too much emphasis can be given to the results which should be treated rather as indicators of possible future trends.

It was disturbing to learn that, although one might be dealing with a promiscuously-biased sample, nearly one-sixth of all the single girls in the series had had an abortion, especially as the women tended to be much less promiscuous than the men. These results were obtained before the passing of the new Abortion Act, so that the majority of these abortions must have been illegal. It is relevant to note that 56 per cent. of a series of 1,000 pregnant girls reported by Diggory (1969) were single. The social consequences are particularly hard for unmarried mothers, of whom there were four in this sample. At a Royal Society of Health Congress held in April 1969, it was stated that in the year ended March 1968, a total of 3,157 illegitimate children had been received into care because the parents could not provide a home. The patients to be noted in this connexion are the fifteen unmarried women who had been pregnant at least once and the fifteen promiscuous women who never or only occasionally used contraceptives. In future it may be useful if such girls can be indentified so that contraceptive techniques or objections to their use can be discussed; it is well recognized that a few highly promiscuous girls can be foci for the transmission of sexually transmitted diseases as well as being responsible for a succession of illegitimate children.

Although it is encouraging to find that 66 per cent. accepted the need for contraceptive advice, the figures seem to suggest that 22 per cent. of all the unmarried women and 25 per cent. of the men never use any form of contraceptive. There is also a dangerous tendency to take chances by the irregular use of contraceptives. The men tended to favour the sheath whereas 49 out of the 89 women favoured the pill, which was chiefly used by the sexually-active promiscuous and the married patients. Withdrawal still appears to be used comparatively often, especially by single patients. The less sexually-active and nonpromiscuous patients were using such methods as the sheath and withdrawal, and were thus more likely to become pregnant than the promiscuous, pillusing, patients. Our findings are comparable to the figures on contraceptive usage in pregnant girls reported by Diggory (1969). In his series 30.5 per cent. normally used no contraceptive and $47 \cdot 8$ per cent. had been completely unprotected at the time of conception; the remainder, except for the 1.2 per cent. taking the pill, had been using fallible methods.

\section{Conclusions}

Ideally a sample should be so drawn that the chances of contracting venereal disease could be shown as a ratio of the frequency of intercourse and the number of partners; nevertheless the figures in this sample undoubtedly point to the need for sex education, and particularly contraceptive advice and counselling advice.

The venereal diseases clinics, because of their special knowledge of patients' sexual behaviour and difficulties, can help to reduce the problems of unwanted pregnancies and promiscuous behaviour as well as the incidence of venereal disease by setting up associated advisory and counselling services with trained counsellors, social workers, and family planning consultants.

There were also indications in our sample that $\mathbf{4 0}$ per cent. of the married patients who had had intercourse in their early teens (before the 18th birthday) had separated from their partner or had been divorced. This appears to demand further enquiry. The suggested counselling and advisory services could include marriage guidance; it seems desirable for comprehensive counselling services to work in close co-operation with centres for the treatment of sexually transmitted diseases.

\section{Summary}

A pilot survey by questionnaire was made to sample the incidence of sexual promiscuity, pregnancy, abortions, and the use of contraception in the cases of patients attending a large venereal diseases clinic in London. 44 men and 89 women completed the questionnaire satisfactorily. Approximately 75 per cent. were unmarried and in the 20 to 30 year age range; 10 per cent. of the women were aged 16 to 19 years. 
Fifteen of the 63 single women had been pregnant and fifteen of 89 women had had at least one abortion, in most cases illegally. 84 per cent. of the men and 41 per cent. of the women were judged to be promiscuous and 43 per cent. of men and 51 per cent. of women had intercourse two to four times a week or more. 25 per cent. of men and 18 per cent. of women never used contraceptives. The pill was used regularly by 49 of the 89 women who were mainly sexually active, promiscuous, and married. 40 per cent. of the married patients who had had intercourse before the age of 18 were separated or divorced.

The authors wish to thank the director, Dr. R. D. Catterall, and the medical, nursing, and administrative staff of James Pringle House for their cooperation, and also Miss C. Goble, Student Health Association, University College, London.

\section{References}

DigGORY, P. L. C. (1969) Lancet, 1, 873

LiNken, A. (1968) Brit. F. vener. Dis., 44, 337

SCHOFIELD, M. (1968) 'Sexual Behaviour of Young People'. Penguin, London

\section{Vagabondage sexuel et contraception dans un échantillon de malades se présentant dans une clinique de maladies vénériennes}

\section{SOMMAIRE}

Une enquête pilote par questionnaire a été faite pour apprécier l'incidence de la promiscuité sexuelle, de la grossesse, des avortements et de l'usage des contraceptifs chez des malades fréquentant une importante clinique vénéréologique de Londres. 44 hommes et 89 femmes remplirent le questionnaire d'une manière satisfaisante. Environ 75 pour cent étaient célibataires et d'un âge de 20 à 30 ans; 10 pour cent des femmes étaient âgées de 16 à 19 ans.

Des 63 femmes célibataires, 15 avaient eté enceintes, et parmi les 89 femmes, 15 avaient eu au moins un avortement, généralement illégal. 84 pour cent des hommes et 41 pour cent des femmes furent considérés comme étant des vagabonds sexuels; 43 pour cent des hommes et 51 pour cent des femmes avaient des rapports sexuels deux à quatre fois, ou plus, par semaine. 25 pour cent des hommes et 18 pour cent femmes n'avaient jamais utilisé de contraceptifs. La pilule était employée régulièrement par 49 des 89 femmes qui, pour la plupart, étaient sexuellement actives, à partenaires multiples, et mariées. 40 pour cent des malades mariés qui avaient eu des rapports avant l'âge de 18 ans étaient séparés ou divorcés. 